\title{
Thermal - Vacuum dehydration and dispergation of dispersed materials
}

\author{
V. Kutovyi ${ }^{\text {a.b }}$ V. Tkachenko ${ }^{\text {a.b. }}$, A. Nikolaenko ${ }^{a}$ \\ ${ }^{a}$ National Science Center "Kharkov Institute of Physics and Technology"1, \\ Akademicheskaya Str., Kharkov, 61108, Ukraine \\ ${ }^{b}$ V. N. Karazin Kharkiv National University, 4, Area of Liberty, Kharkov, 61077, \\ Ukraine, Tel.: +38 05734910 82, \\ E-mail:kutovoy@kipt.kharkov.ua
}

\begin{abstract}
Scientific and technical studies on the intensification of removal moisture from dispersed materials and their simultaneous dispergation in the hollow heating element of a thermo-vacuum apparatus is researched. Continuous thermovacuum dehydration and dispergation process of zirconium hydroxide, brown coal, graphite, sawdust, biological materials is considered. Based on conducted studies was made conclusions about perspective to use this technology. Thermo-vacuum technology is different from the other by lowtemperature heating, low time processing, humidity indicators controlling and nano-dispersion grinding.
\end{abstract}

Keywords: dehydration, dispergation, energy saving 


\section{Introduction}

Intensification of production processes as well as solution the problems of energy and resource saving at dehydration of dispersed materials has become increasingly important in recent times.

There are drying installations in which the mechanical process of dispersion and dehydration of dispersed material are used in parallel; it leads to intensification of the process and reduction in capital expenditures [1]. In this case, preheated air is used as a drying agent.

In the paper [2] it is shown, that a significant amount of heat is released at fine grinding of materials in impact-reflective mills. This phenomenon is associated with impact and friction of material particles on working surfaces of the mill, emergence of new surfaces during destruction and also due to turbulence of the dust-gas mixture in the working zone of the mill.

Thus, heat occurrence in the process of fine grinding in impact-reflective mills ensures in parallel the processes of dehydration and dispersion of various materials.

However, due to lack of a rational technology for performing dehydration and dispersion in parallel, such processes have not became widely used in practice, especially in chemical technology.

There are various methods and devices designed for dehydration of agricultural dispersed materials $[3,4]$. However, they require considerable energy consumption and do not ensure obtaining a product with specified characteristics, in particular, dispersion and humidity which largely affect its quality.

\section{Materials and methods}

Thermal-vacuum energy-efficient pulse-impact method for continuous dehydration and dispersion of wet materials has been developed on the basis of the performed theoretical and experimental studies. The proposed method is based on the principle of combining the rapid evacuation and thermal heating upon direct contact of a wet material with a heated surface of the spiral heater, which provides instantaneous heating of wet material particles in vacuum to a specified temperature. The contact of the wet material with the heated wall of the heater causes heat transfer from the heater wall to the surface layer of the material, and the reduced pressure inside the heating element allows moisture to be removed from the material at a temperature substantially below the vaporization temperature at atmospheric pressure. The rate of destruction of the surface layer of the wet material depends on the heating temperature and its internal state.

The thermal-vacuum installation for continuous dehydration and dispersion is presented in Fig. 1 [5].

The installation consists of a feed hopper (1), hollow heater (2), vacuum pump (3), pipelines $(4,11)$, cyclone (5), receiver of dried raw materials (6) and rotary valve (7). It has thermocouples $(8,13)$, control panel (9), conveyor (10), filter (12), level sensor for dried raw material (14), vacuum gauge (15). 
This installation design provides simultaneously both high-performance continuous dehydration and dispersion of material in heat insulated space.

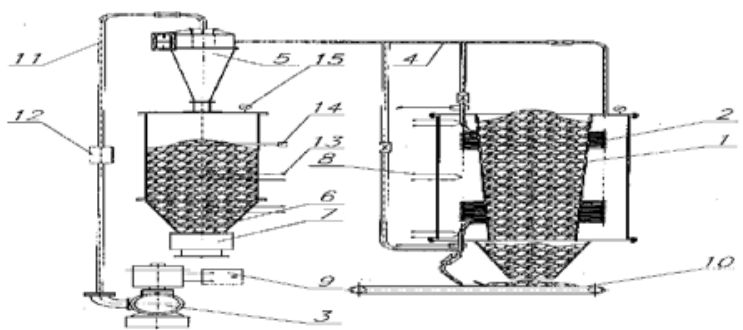

Fig. 1. Diagram of the thermal-vacuum installation

\section{Results}

\subsection{Dehydration and dispersion of zirconium hydroxide}

Let us consider a continuous process of production of zirconium dioxide fine-dispersed powder from zirconium hydroxide in a thermal-vacuum installation. The initial humidity of zirconium hydroxide is $80 \%$, the diameter is $6 \mathrm{~mm}$, the length is within the range of $10-15$ mm. Zirconium hydroxide together with an air enter the lower cavity of the heating element. The rate of a two-phase flow in the thermal-vacuum installation is determined from the expression:

$$
v=\frac{\pi \cdot r^{2} \cdot d^{2} \cdot P \cdot \rho \cdot v_{1}}{2 \cdot \beta \cdot l \cdot \eta},
$$

where, $v$ - rate of a two-phase flow in the heating element, $\mathrm{m} / \mathrm{s}$;

$r$ - internal radius of the heating element, $\mathrm{m}$; $d$-diameter of the particle to be dried, $\mathrm{m}$; $P$ - average pressure in the heating element, $\mathrm{Pa}$;

$\rho$ - medium density $\mathrm{kg} / \mathrm{m}^{3} ; v_{1}$ - hovering rate, $\mathrm{m} / \mathrm{s}$;

$\beta$ - friction coefficient, $\mathrm{kg} / \mathrm{s} ; l-$ the heater length, $\mathrm{m} ; \eta$ - coefficient of air dynamic viscosity, Pa s.

Moving inside the heating element of the thermal-vacuum installation (Fig. 1) the zirconium hydroxide granules (Fig. 2, a) come into contact with heated walls of the heater.

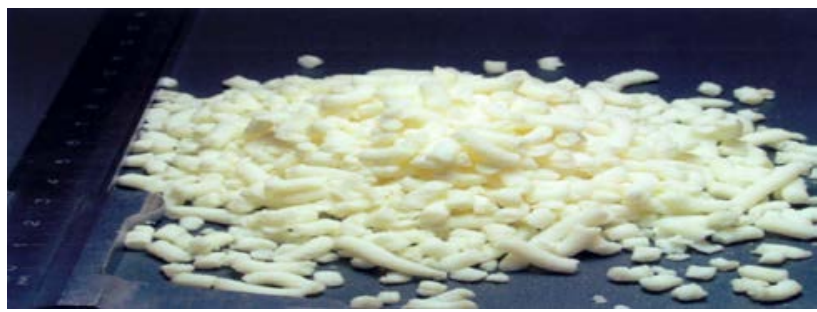

Fig. 2, a. Zirconium hydroxide 


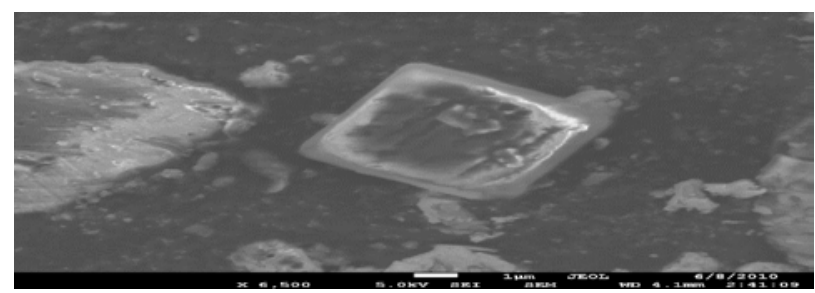

Fig. 2, b. Zirconium dioxide

An instantaneous heating of zirconium hydroxide to a temperature $T_{1}$, which is above the evaporation temperature T2 (T1> T2), occurs. Local intensive vapor emission occurs inside the body of zirconium hydroxide granules under reduced ambient pressure. An instantaneous pressure gradient occurs as a result of vapor emission and zirconium hydroxide granule falls into small particles, which increases liquid removal from the material to be dried. Zirconium hydroxide with an initial humidity of $80 \%$, diameter of 6 $\mathrm{mm}$ and length of $10 \ldots 15 \mathrm{~mm}$ turns into a fine-dispersed powder of zirconium dioxide with moisture of $1 \%$, fraction of $0.1-10 \mu \mathrm{m}$. There are no conglomerates in this powder. (Fig.2, b). The process of zirconium dioxide obtaining from zirconium hydroxide in thermal-vacuum installation takes 15 seconds.

The moisture $\left(m_{\text {вл }}\right)$ removed from the material to be dried in the thermal-vacuum installation is directly proportional to the heater power $\left(P_{\mathrm{H}}\right)$, the heating temperature of the material to be dried $(T)$, the coefficient of heat exchange between the heating element and the material to be dried $(a)$, the evaporation area $(S)$. It is inversely proportional to the environment pressure $\left(P_{c}\right)$, the vapor kinematic viscosity $(v)$, the impact elasticity of the material to be dried $(W)$, the volume of the material to be dried $(V)[6]$.

$$
m_{\text {вл }}=\frac{2 \cdot\left(m_{\text {общ }}-m_{c}\right) \cdot P_{H} \cdot T \cdot a \cdot S}{P_{c \cdot} \cdot v \cdot W \cdot V}, \text { (2) }
$$

where, $m_{\text {total }}-$ total mass of the wet material, $\mathrm{kg} ; m_{\mathrm{c}}-$ mass of the material during dehydration, kg.

\subsection{Dehydration and dispersion of brown coal}

Dehydration and dispersion of brown coal (Fig. 3, a) in thermal-vacuum installation reduces the content of sulfur and nitrogen in coal, which leads to decreasing the amount of harmful emissions into the atmosphere during its combustion. The minimum particle size of the dried coal was $40 \mathrm{~nm}$ (Fig. 3, b), the moisture content was less than $2 \%$. The moisture of the initial stock was $40 \%$, the size - $6 \mathrm{~mm}$. Drying the brown coal took $14 \mathrm{~s}$, its color varied from brown to black. The temperature of the dried brown coal at the heating element output did not exceed $76^{\circ} \mathrm{C}$. At the same time, the quantity of energy expended for dehydration and dispersion of brown coal does not exceed $600 \mathrm{MJ}$ 


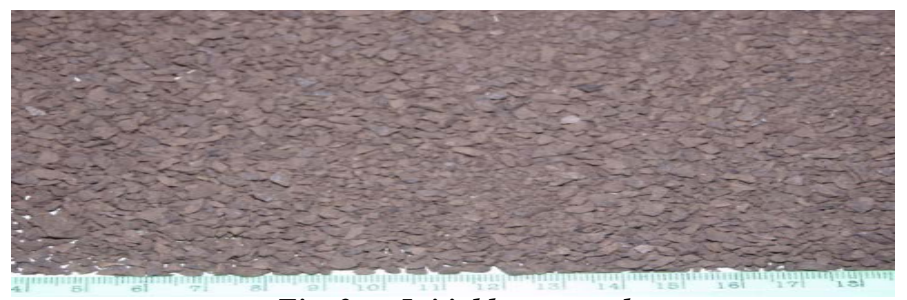

Fia. 3. a. Initial hrown coal

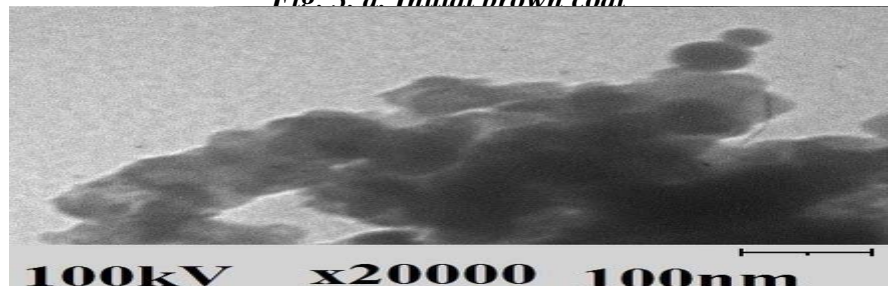

$1001 \times Y \quad \times 20000100 m m$

Fig. 3, b. Electron microscopy of dried brown coal

\subsection{Dehydration and dispersion of graphite}

Nano-dispersed graphite of size 10 - $40 \mathrm{~nm}$ was obtained from fine-dispersed graphite in the thermal-vacuum installation (Fig. $4 \mathrm{a}, \mathrm{b}$ ). The processing time was 15 s. The process was continuous. The quantity of energy expended for dehydration and dispersion of graphite was 320 MJ / t.

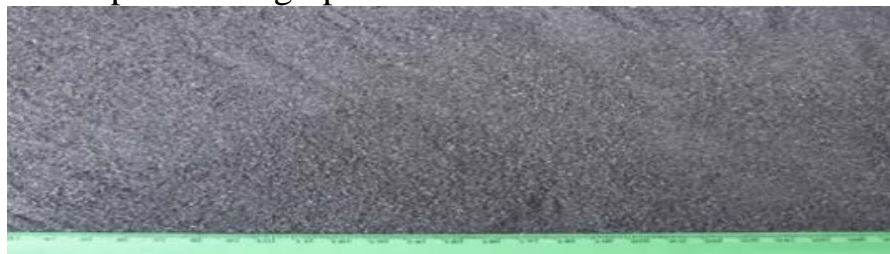

Fig. 4, a. Initial graphite

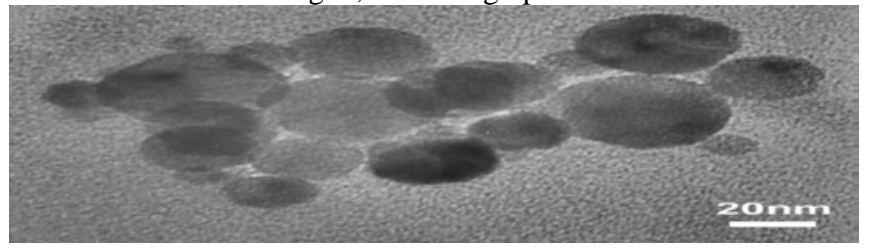

Fig. 4, b. Graphite processed in thermal-vacuum installation

\subsection{Dehydration and dispersion of sawdust}

An energy-saving, highly effective thermal-vacuum technique of continuous dehydration of wood-working industry wastes was developed. Dehydration of wet sawdust depending on the temperature of the heating element was studied. The quantity of thermal energy expended for dehydration did not exceed $360 \mathrm{MJ} / \mathrm{t}$. Dried pine-tree sawdust and its 
moisture content depending on the temperature of the heating element in the thermalvacuum installation is presented in

Fig. 5 (b, d, g). The sawdust initial humidity is 70\%. (Fig. 5, a).

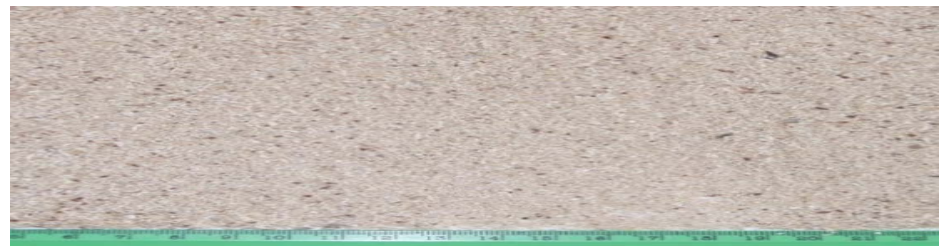

Fig. 5, a. Initial sawdust Humidity 70\%

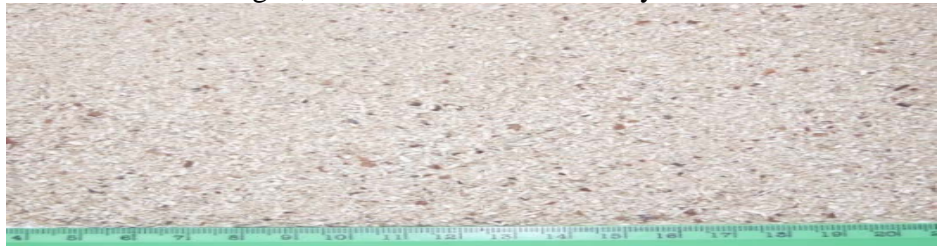

Fig. 5, b. Heater temperature $150^{\circ} \mathrm{C}$, Humidity $20 \%$

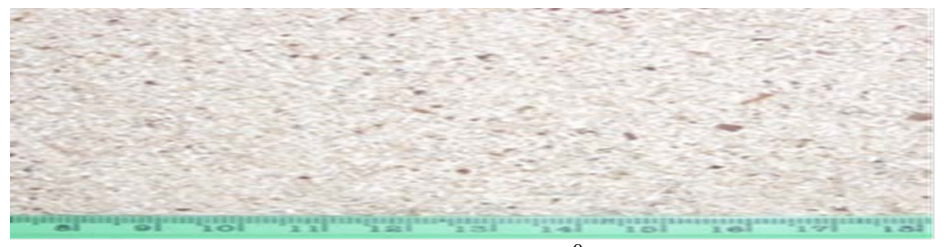

Fig. 5, d. Heater temperature $200^{\circ} \mathrm{C}$, Humidity $5 \%$

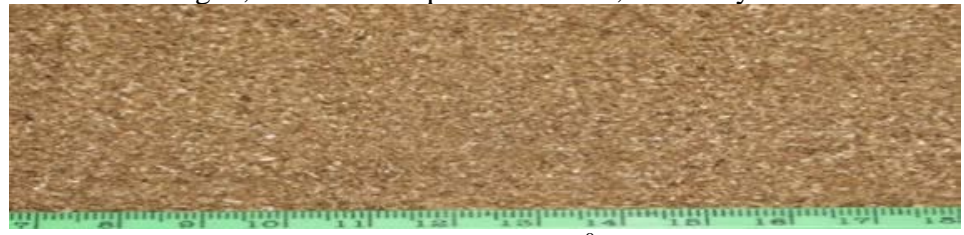

Fig. 5, g. Heater temperature $250^{\circ} \mathrm{C}$, Humidity $1 \%$

Sawdust dehydration in the thermal-vacuum installation lasts for $20 \mathrm{~s}$, the process is continuous.

\subsection{Dehydration and dispersion of agricultural products}

Dehydration of sugar production waste was carried out in the thermal-vacuum installation. The initial humidity was $65 \%$. Fig. 6, a. The temperature of the dried beet pulp did not exceed $50^{\circ} \mathrm{C}$. Humidity - 5\%. Fig. 6, b. Dehydration time was 20 c. The process was continuous. Nutritive substances are kept. The quantity of thermal energy expended for dehydration was equal to $720 \mathrm{MJ} / \mathrm{t}$. 


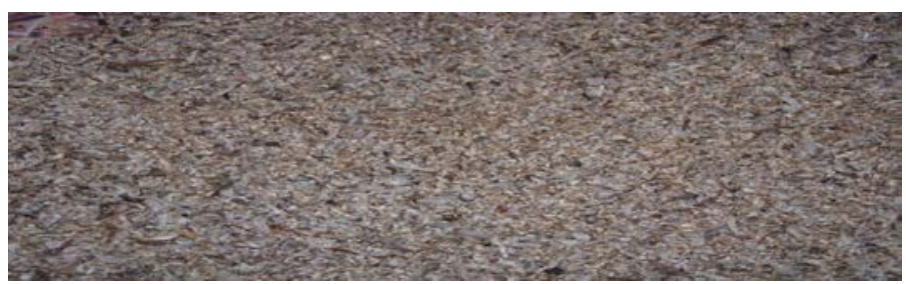

Fig. 6, a. Initial pulp

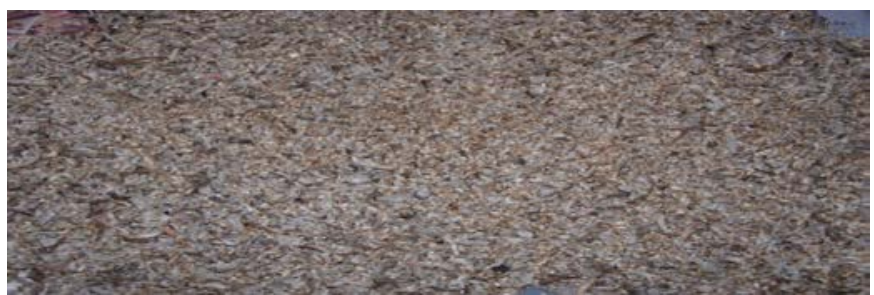

Fig. 6, a. Dried pulp

Thermal-vacuum drying of alfalfa with humidity of $48 \%$ is presented in Fig. 7 , a. After drying the alfalfa moisture was $12 \%$. See Fig. 7, b. Drying time was 20s. Nutritive substances were kept. Heat energy consumption was $580 \mathrm{MJ} / \mathrm{t}$

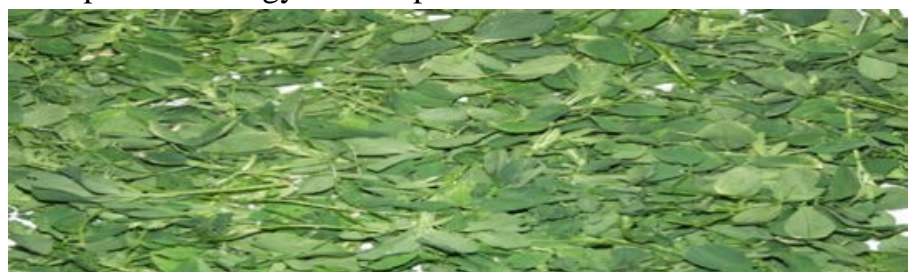

Fig. 7. a. Initial alfalfa

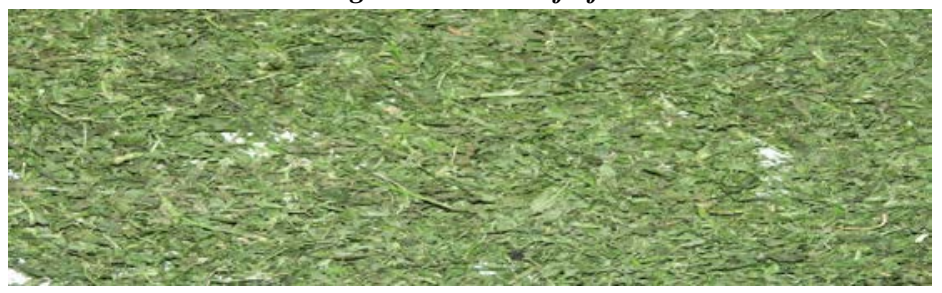

Fig. 7. b. Dried alfalfa

The results of study on moisture removal from dispersed materials depending on mode parameters of the thermal-vacuum installation made it possible to create an industrial science and technology base for developing energy-efficient thermal-vacuum installations, to define requirements for optimizing the technological processes of dispersed materials dehydration taking into account their physicochemical and structural compositions, to reduce energy cost per unit of the dried product, to speed up the dehydration process, to develop a highly efficient termal-vacuum technology of production of fine-dispersed 
materials of high purity, to keep quality and ecological purity of the products obtained. This method allows simultaneously to remove moisture from the dispersed material and to disperse it.

The development results are of current interest for updating the existing and creation of new thermal-vacuum drying installations.

\section{Conclusions}

1. Scientific and technical studies on the intensification of removal moisture from dispersed materials: zirconium hydroxide, brown coal, graphite, sawdust, biological materials are researched. The regularities of heat exchange processes between heating element and wet dispersed material in the hollow spiral-heating element of the thermo-vacuum apparatus are established. Demonstrated that in thermo-vacuum apparatus by 15 seconds it possible to obtain dried nano-dispersed materials.

2. A low-temperature thermo-vacuum dehydration technology of biological materials was developed. Conducted studies demonstrated that most optimal, from the point of view of preserving biological material quality, is dehydration mode at temperatures up to $50{ }^{\circ} \mathrm{C}$.

3. Conducted scientific and technical studies are relevant to improve existing equipment and creation of new heat-technological equipment.

\section{References}

[1] Shishkov, N.I.; Oparin, S.A.; Soroka; P.I.; Zrazhevskij, V.I; Issledovanie sovmeshhennyx processov izmelcheniya i sushki $\mathrm{v}$ melnice udarnootrazhatelnogo dejstviya. Materiali V Mizhnarodnoï naukovo-praktichnoï konferenciï "Nauka i osvita, 2002 (19), Dnipropetrovsk - Doneck, 2002, 49-50.

[2] Pat. №88108 Ukraïna, MPK S 01 V31/36. Sposib oderzhannya karbidu kremniyu / Soroka P. I., Bila A. O. ta in.; zayavnik ta patentovlasnik DVNZ «UDXTU».-№ a 200802934; zayavl.06.03.08; opubl.10.09.09, Byul.№ 17, 6 .

[3] Oparin, S.; Leshhenko, V.; Soroka, P. Raschet texnologicheskix parametrov processa izmelcheniya $\mathrm{v}$ melnice udarno-otrazhatelnogo dejstviya, Naukovi praci ONAXT., 2010, (37), 118-122.

[4] Pat. №96082 Ukraïna MPK V02S13/14 Vidcentrovij mlin udarnoï diï / Soroka P. I., Oparin S. O.; zayavnik ta patentovlasnik DVNZ «UDXTU». - № a 2001096302. Zayavl. 25.05.2010. - Opubl. - 27.12.2010. - Byul. №18.

[5] International Patent, a20507488 27.07.2005 UA, MПK F26B5/04; F26B23/06; F26B23/00. Apparatus for Drying of Wet Dispersed Raw Materials. / V.O. Kutovyi. \#PCT/UA2005/000051; Filling. 15.01.2005; Pudlic. 01.02.2007; Publication number W0/2007/013866. - 6p.

[6]Kutovyi, V.; Lutsenko, A.; Skoromnaya, S.; Tkachenko, V. Physical model of simultaneous disparaging and dehydration of fine porous material in thermal vacuum installation, Energy, Energy Saving and Rational Nature Use, 1-2 (7, 8), 2017, 5-16. 